\title{
Prospective and longitudinal long-term employment outcomes after resective epilepsy surgery \\ OPEN
}

Anna Edelvik, MD

Roland Flink, MD, PhD

Kristina Malmgren, MD, $\mathrm{PhD}$

Correspondence to

Dr. Edelvik:

anna.edelvik@vgregion.se
Supplemental data at Neurology.org

\section{ABSTRACT}

Objective: To investigate long-term employment outcomes after resective epilepsy surgery in a national population-based cohort of adults.

Methods: In the Swedish National Epilepsy Surgery Register, all adults who were operated with resective epilepsy surgery from 1995 to 2010 were identified. Two-year follow-up was available for 473/496, 5-year follow-up for 220/240, 10-year follow-up for 240/278, and 15-year follow-up for 85/109 patients.

Results: There were no significant changes in employment outcome over time at group level, but for those with full-time employment at baseline, 79\%, 79\%, 57\%, and $47 \%$ of seizure-free patients were in full-time work at 2-, 5-, 10-, and 15-year follow-up, compared to patients with benefits at baseline, where 16\%, 27\%, 31\%, and 33\% of seizure-free patients worked full time at these time points ( $p=0.018$ at 10 years). More patients with full-time work had ability to drive, a family of their own, and higher educational status than patients in part-time work or on benefits. Univariate predictors for employment at long term were having employment preoperatively, higher education, favorable seizure outcome, male sex, and younger age at surgery. Multivariate predictors were having employment preoperatively, favorable seizure outcome, and younger age.

Conclusions: The best vocational outcomes occurred in seizure-free patients who were employed or students at baseline, which may reflect a higher general psychosocial level of function. Younger age also predicted better employment outcomes and it therefore seems plausible that early referral for surgery could contribute to better vocational outcomes. Neurology ${ }^{\circledR}$ 2015;85:1482-1490

\section{GLOSSARY}

AED = antiepileptic drug; $\mathbf{B}$ = benefits/unemployed; $\mathbf{F W}$ = full-time work; $\mathbf{O R}$ = odds ratio; $\mathbf{P W}$ = part-time work; $\mathbf{S}$ = full- or part-time studies; SNESUR = Swedish National Epilepsy Surgery Register

Long-term studies on employment outcomes after resective epilepsy surgery are scarce. Most are retrospective and cross-sectional and focus on patients who have had temporal lobe resections. Some investigators found no change in the number of employed patients after surgery, ${ }^{1-5}$ others found a decrease in employment for patients with continuing seizures but no change for seizurefree patients, ${ }^{6}$ while some reported increased employment. ${ }^{7-10}$ Knowledge about employment outcomes after epilepsy surgery is of considerable importance, both from health economic aspects and in relation to quality of life. ${ }^{11,12}$ Many patients have high expectations on epilepsy surgery, and ability to work or work more is a common wish. ${ }^{13}$ Especially for patients who are unemployed before surgery, it can take several years until they become employed, ${ }^{7}$ and longitudinal long-term studies are needed. No previous study has compared employment levels with those in the general population.

The Swedish National Epilepsy Surgery Register (SNESUR) provides an opportunity to study epilepsy surgery outcomes prospectively and longitudinally at a population-based level. ${ }^{14-19}$

\footnotetext{
From the Department of Clinical Neuroscience and Rehabilitation (A.E., K.M.), Institute of Neuroscience and Physiology, Sahlgrenska Academy, University of Gothenburg; and Department of Clinical Neurophysiology (R.F.), Uppsala University Hospital, Sweden.

Go to Neurology.org for full disclosures. Funding information and disclosures deemed relevant by the authors, if any, are provided at the end of the article. The Article Processing Charge was paid by the Swedish Research Council.

This is an open access article distributed under the terms of the Creative Commons Attribution-NonCommercial-NoDerivatives License 4.0 (CC BY-NC-ND), which permits downloading and sharing the work provided it is properly cited. The work cannot be changed in any way or used commercially.
} 
The aim of this study was to explore employment outcomes at long term after resective epilepsy surgery in adults, to relate these to seizure outcome, and compare the results with employment in the general population. A further aim was to investigate predictors of staying employed or gaining employment.

METHODS The SNESUR is a national collaboration among all 6 epilepsy surgery centers in Sweden. It started in 1990 and is completely prospective since 1995 . All epilepsy surgery procedures in Sweden are reported, making the register populationbased. The register is subject to regular internal and external quality controls. Patients with suspected low-grade tumors (World Health Organization grades I-II) are included provided that the reason for surgery is drug-resistant epilepsy. Should histopathology disclose higher malignancy, they are excluded from SNESUR. Data are collected at baseline and after 2 years and comprise information on epilepsy history, seizure frequency, antiepileptic drugs (AEDs), psychosocial data, preoperative investigations, surgical data, histopathology, and surgical complications. Long-term follow-up using structured telephone interviews was initiated in 2005, and is performed 5, 10, and 15 years postsurgery. Psychosocial data include information on education, employment, and social security status, family and living conditions, and driving.

For this study, all adult patients (older than 18 years) who had resective epilepsy surgery in Sweden from 1995 to 2010 were included. In the entire cohort, $473 / 496$ patients (95.4\%) had 2-year follow-up, while 220/240 (91.7\%) operated 2000-2007 had 5-year follow-up; 240/278 (86.3\%) operated 1995-2002 had 10-year follow-up and 85/109 (78.0\%) operated 19951997 had 15-year follow-up. See figure e-1 on the Neurology ${ }^{B}$ Web site at Neurology.org for flowchart and details on reoperations, deaths, and missing patients.

Employment status is classified into the following categories: full-time work (FW), part-time work (PW), full- or part-time studies (S), entirely on benefits, including sick leave and unemployment (B), or retired, i.e., old-age pension. Only 2 patients were full-time homemakers and they were excluded from analysis.

Seizure outcome is described as change in seizure frequency in relation to mean monthly seizure frequency the year before preoperative investigations. Outcome is categorized into seizure freedom, $\geq 75 \%$ reduction, $50 \%-74 \%$ reduction, and $<50 \%$ reduction in seizure frequency. Seizure freedom is defined as being seizure-free with or without aura at least the year preceding the follow-up at each time point, i.e., 2, 5, 10, and 15 years after surgery (International League Against Epilepsy classes 1 and 2). ${ }^{20}$ Ability to drive is defined as being seizure-free and having a driver's license or being in the process of obtaining one.

Data were obtained from Statistics Sweden on the work situation in the general population during 2005 to 2010 (the Labour Force Surveys). Full-time employment is defined as working $\geq 35$ hours per week and part-time employment as working $<35$ hours per week. Data from the Labour Force Surveys were stratified into 4 age groups of decades between ages 25 and 64 and compared with seizure-free patients in each age group.

To assess whether drug load influenced employment outcomes, AED treatment (number of AEDs) was related to vocational outcome. Since the number of AEDs can be considered a proxy for disease severity, this was analyzed only for seizure-free patients.

In the logistic regression analysis, predictors for employment were sought, based on findings in earlier studies ${ }^{3,7,21-23}$ and our own preliminary results from SNESUR. ${ }^{24}$ The following variables were investigated: seizure outcome, preoperative vocational status, preoperative level of education, age (per decade of life), epilepsy duration in percent of life length (in order to compensate for the effect of age), any neurologic dysfunction (including intellectual disability with a Full Scale IQ $<70$ ), sex, presence of secondary generalized tonic-clonic seizures, and mean preoperative seizure frequency of $\geq 30$ seizures per month.

Standard protocol approvals, registrations, and patient consents. This study was approved by the Regional Board of Medical Ethics at the University of Gothenburg. The board considered long-term follow-up after epilepsy surgery as a qualitycontrol measure not necessitating individual consent.

Statistical analysis. For comparison between 2 groups, Fisher exact test was used for dichotomous variables, Mann-Whitney $U$ test for continuous variables, and Mantel-Haenszel $\chi^{2}$ test for ordered categorical variables. All tests were 2-tailed and conducted at the $5 \%$ significance level.

Univariate binary logistic regression was performed for each variable to predict being employed (full- or part-time) vs unemployed, receiving benefits, or studying at each time point. In these analyses, retired patients were excluded and seizure outcome was dichotomized into being seizure-free or not the year preceding follow-up.

Forward stepwise multivariate logistic regression was conducted for predictors with $p<0.10$ in the univariate analysis. Statistical analysis was performed using IBM SPSS Statistics 19 (IBM Corp., Armonk, NY) and SAS 9.2 (SAS Institute, Cary, NC).

RESULTS Baseline characteristics and types of surgery of the patient cohorts are shown in table 1 .

Employment outcomes. Employment status at baseline and at each postoperative follow-up is shown in table $\mathrm{e}-1 \mathrm{~A}$. At group level there was very little change in employment status, but with time the numbers of students decreased and of retired patients increased.

Employment outcomes after 2, 5, 10, and 15 years for the 4 baseline groups FW, PW, S, and B are illustrated in detail in figure 1 . Each group has been further stratified into subgroups based on seizure outcome at the same time point of follow-up.

Patients who worked full time before surgery (FW group) had the most favorable employment outcome and the strongest correlation to seizure outcome, but the proportion who worked full time decreased over time, with $79 \%, 79 \%, 57 \%$, and $47 \%$ of seizure-free patients working full time at 2, 5, 10, and 15 years postoperatively. Approximately $80 \%$ of patients who became seizure-free or had $\geq 75 \%$ seizure reduction worked at least part time more than 10 years after surgery.

For patients in part-time work at baseline (PW group), the results were less consistent. After 2 and 5 years, respectively, $18 \%$ and $32 \%$ of those who were seizure-free had full-time work, but about the same proportion were now on benefits. Ten and 15 years after surgery, $23 \%$ and $29 \%$ of seizure-free patients worked full time. Many patients with less favorable seizure outcome continued to work part time long after surgery. 
Table 1 Baseline characteristics and types of surgery for patient cohorts

\begin{tabular}{|c|c|c|c|c|}
\hline & \multicolumn{4}{|l|}{ Cohort } \\
\hline Total no. & 473 & 220 & 240 & 85 \\
\hline Sex, M/F (\% M) & $224 / 249(47.4)$ & $102 / 118(46.4)$ & $112 / 128(46.7)$ & $40 / 45(47.1)$ \\
\hline Age, y & 36.5 (10.9); 35.4 (18-69) & 37.7 (10.9); 37.3 (19-69) & 37.1 (11.2); 36.6 (18-67) & 36.5 (10.7); 34.6 (19-67) \\
\hline Monthly seizure frequency & $\begin{array}{l}34.6(168.2) ; 10.0 \\
(0.1-3300)\end{array}$ & $\begin{array}{l}42.1(233.1) ; 10.0 \\
(0.1-3300)\end{array}$ & $\begin{array}{l}44.0(233.0) ; 10.0 \\
(0.1-3300)\end{array}$ & $\begin{array}{l}32.2(108.9) ; 10.0 \\
(0.5-960)\end{array}$ \\
\hline Minor intellectual disability, ${ }^{a} \mathrm{n}(\%)$ & $25(5.3)$ & $10(4.5)$ & $14(5.8)$ & $5(5.9)$ \\
\hline No. of AEDs at baseline & $1.9(0.8) ; 2(0-6)$ & $2.0(0.8) ; 2(0-5)$ & $1.9(0.8) ; 2(0-6)$ & $1.8(0.7) ; 2(0-3)$ \\
\hline Epilepsy duration, y & $19.7(12.2) ; 17.9(0.3-54.4)$ & 20.2 (13.0); $17.0(0.3-54.4)$ & $20.4(12.2) ; 18.8(0.4-52.5)$ & 21.4 (11.5); $19.8(1.0-50.4)$ \\
\hline \multicolumn{5}{|l|}{ Employment status, \% } \\
\hline Benefits/unemployed & 35.3 & 34.1 & 32.5 & 34.5 \\
\hline Neurologic deficit, ${ }^{\mathrm{b}} \mathrm{n}(\%)$ & 59 (12.5) & $20(9.2)$ & 27 (11.3) & 11 (12.9) \\
\hline \multicolumn{5}{|l|}{ Type of surgery, $n$ (\%) } \\
\hline TLR & $368(77.8)$ & $166(75.5)$ & $197(82.1)$ & 69 (81.2) \\
\hline FLR & 63 (13.3) & 30 (13.6) & $29(12.1)$ & $12(14.1)$ \\
\hline P/OLR & $31(6.6)$ & $22(10.0)$ & 9 (3.8) & $2(2.4)$ \\
\hline ML/HE & $11(2.3)$ & $2(0.9)$ & 5 (2.1) & $2(2.4)$ \\
\hline
\end{tabular}

Abbreviation: $\mathrm{AED}=$ antiepileptic drug; $\mathrm{FLR}=$ frontal lobe resection; $\mathrm{ML} / \mathrm{HE}=$ multilobar resection or hemispherectomy; $\mathrm{P} / \mathrm{OLR}=$ parietal or occipital lobe resection; TLR = temporal lobe resection.

Unless otherwise indicated, data represent mean (SD); median (minimum-maximum).

${ }^{a}$ Minor intellectual disability = IQ 50-69. No patient had a major intellectual disability (IQ $<50$ ).

${ }^{\mathrm{b}}$ Motor/cerebral palsy, dysphasia, visual, or auditory impairment. Intellectual disability and autism disorders not included.

Being a student preoperatively ( $S$ group) and becoming seizure-free was associated with good employment outcome. Two years after surgery, $31 \%$ of seizure-free patients worked full time, but many were still studying. After 5 and 10 years, 58\% and $59 \%$ of those seizure-free had full-time work, which was comparable to patients working full time at baseline.

In the group of patients who were not employed or studying preoperatively (B group), 27\%, 31\%, and $33 \%$ of those seizure-free worked full time 5 , 10 , and 15 years after surgery, respectively. Fewer patients worked part time and most of those who did not become seizure-free were on benefits.

Comparisons to employment status in the general population. Data comparing full-time employment for all patients and the general Swedish population are shown in table e-1B. The results are shown in 4 age groups of decades up to age 64. Comparisons between the general population and seizure-free patients are illustrated in figure 2 . In the general population, $65 \%$ to $71 \%$ of those between 25 and 54 worked full time, decreasing to $53 \%$ for people aged 55 to 64 years. This can be compared with the seizure-free patients with 5- and 10-year follow-up after surgery, where $36 \%$ to $65 \%$ worked full time up to age 54 , but thereafter only $24 \%$ to $27 \%$.

Social factors associated with employment. Preoperative educational level and preoperative vocational status were associated; $66 \%$ of those with high school or university education worked preoperatively, compared to $43 \%$ of patients with only compulsory schooling $(p<0.0001)$. Ten years postoperatively, $59 \%$ with university education worked full time, $42 \%$ part time, and $11 \%$ were receiving benefits. For patients with only compulsory schooling, $14 \%$ were in full-time work, $18 \%$ in part-time work, and $56 \%$ receiving benefits after 10 years $(p=0.0005)$.

For seizure-free patients, ability to drive after 5, 10, and 15 years was associated with favorable employment status, where $82 \%$ with full-time employment vs $52 \%$ of those on benefits had ability to drive ( $p=$ $0.019)$ at 5 years. The corresponding numbers at 10 years were $79 \%$ and $46 \%(p=0.017)$. At 15 -year follow-up, the differences were less pronounced (78\% and 58\%) and nonsignificant $(p=0.491)$.

At 10 years, $74 \%$ of those with full-time employment had a family of their own while $24 \%$ were 
A Full-time employment at baseline

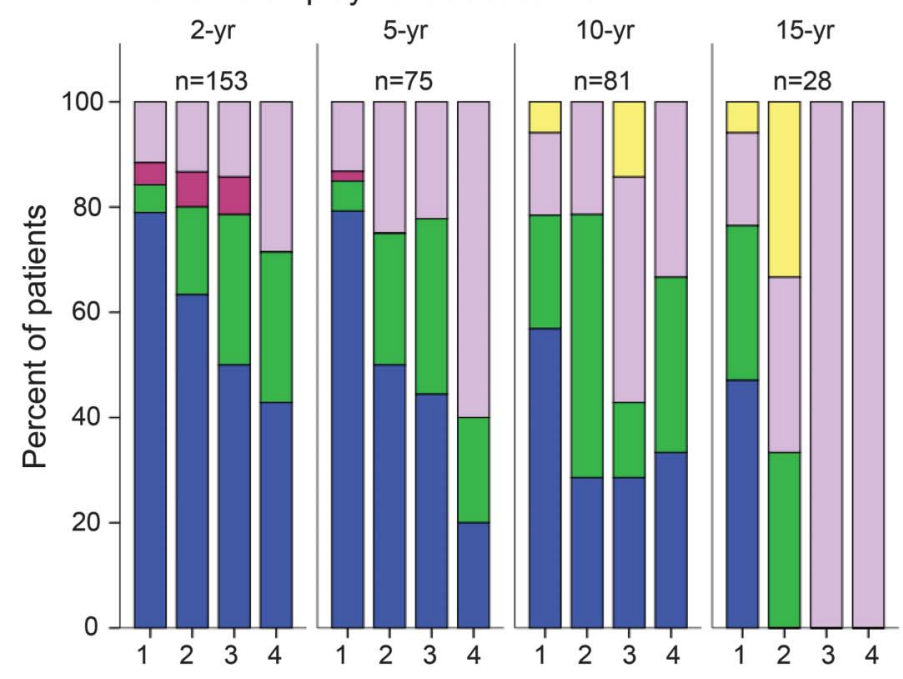

C Students at baseline

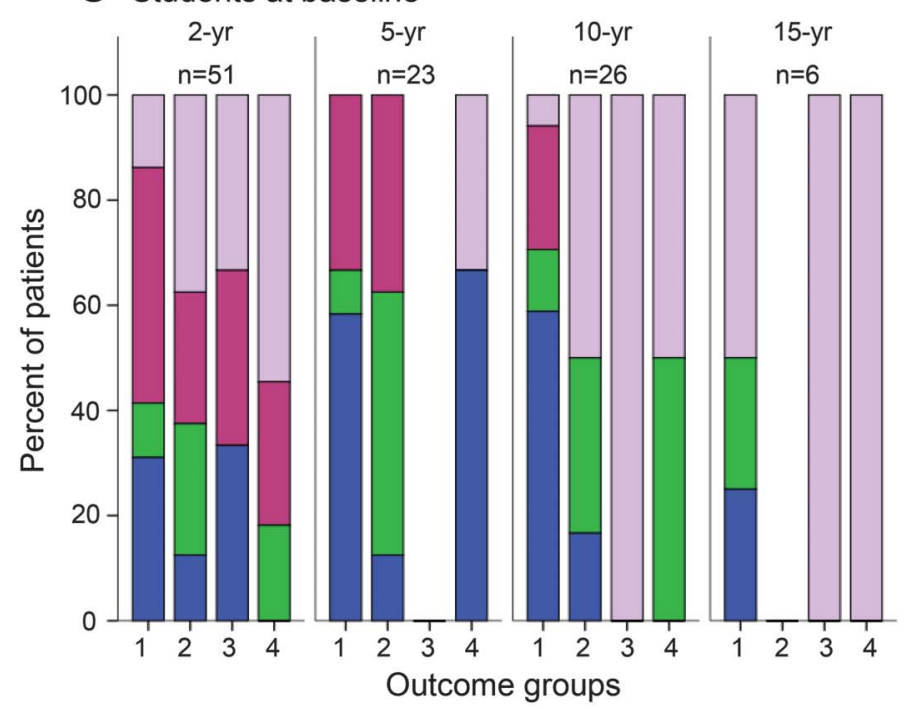

Outcome groups:

1. Seizure-free

2. $>75 \%$ seizure reduction

3. $50-75 \%$ sz reduction

4. $<50 \%$ sz reduction
B Part-time employment at baseline

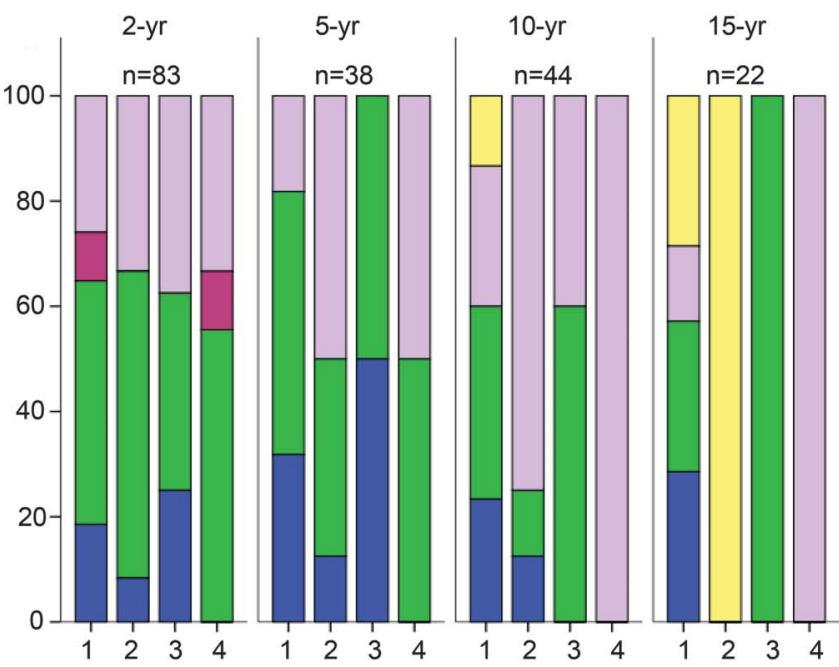

D Benefits at baseline
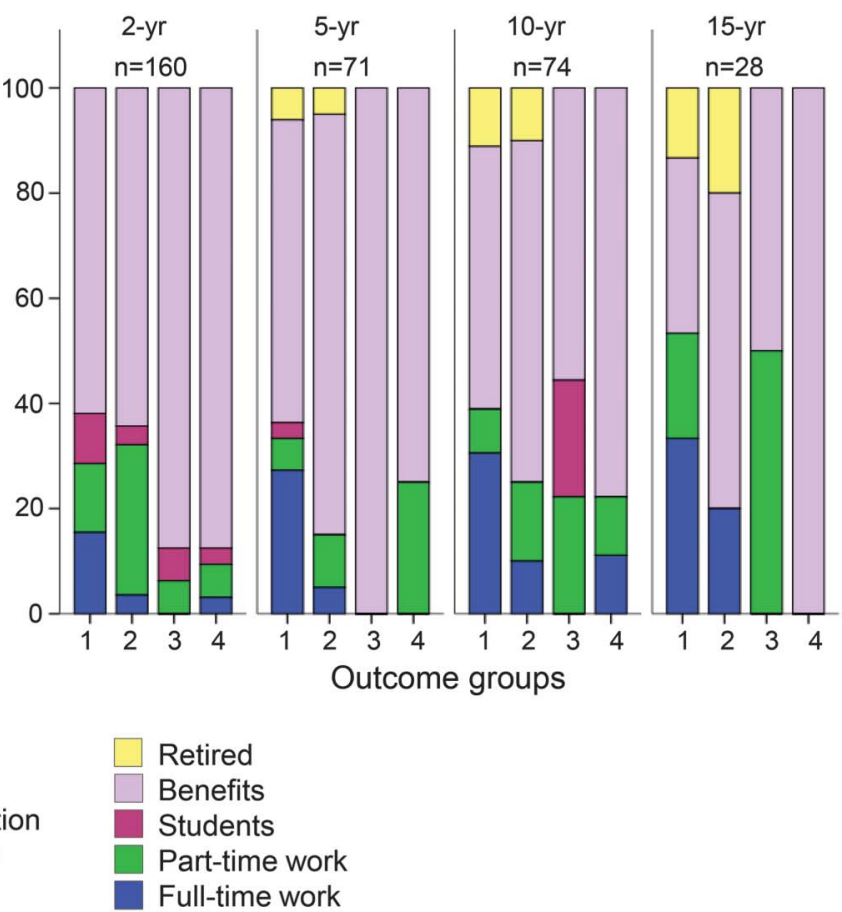

Seizure-free = seizure-free the year before follow-up; sz reduction = reduction in seizure frequency compared with baseline

single. Of those working part time, $55 \%$ had a family, $38 \%$ were single, and $6 \%$ lived with their parents. Among those with benefits, 55\% had a family, 32\% were single, $7 \%$ lived with parents, and $6 \%$ lived in care-taking homes.

The number of AEDs and employment (full time or part time) were analyzed for seizure-free patients (table e-2). At 5 years, $41 \%(33 / 81)$ of those employed and 28\% (10/36) of those not employed had ceased AED medication ( $p=$ 0.021 ). At 10 and 15 years, this difference was no longer seen.
Predictors for employment. Logistic regression analyses were performed for the prediction of being employed (full or part time) vs either studying or receiving benefits postoperatively. Statistically significant univariate variables varied somewhat at different time points, but included seizure freedom, shorter duration of epilepsy, $<30$ seizures per month preoperatively, male sex, younger age at surgery, having employment preoperatively, and higher education (see figure 3). Multivariate predictors were preoperative employment, seizure freedom, and younger age (table 2). 


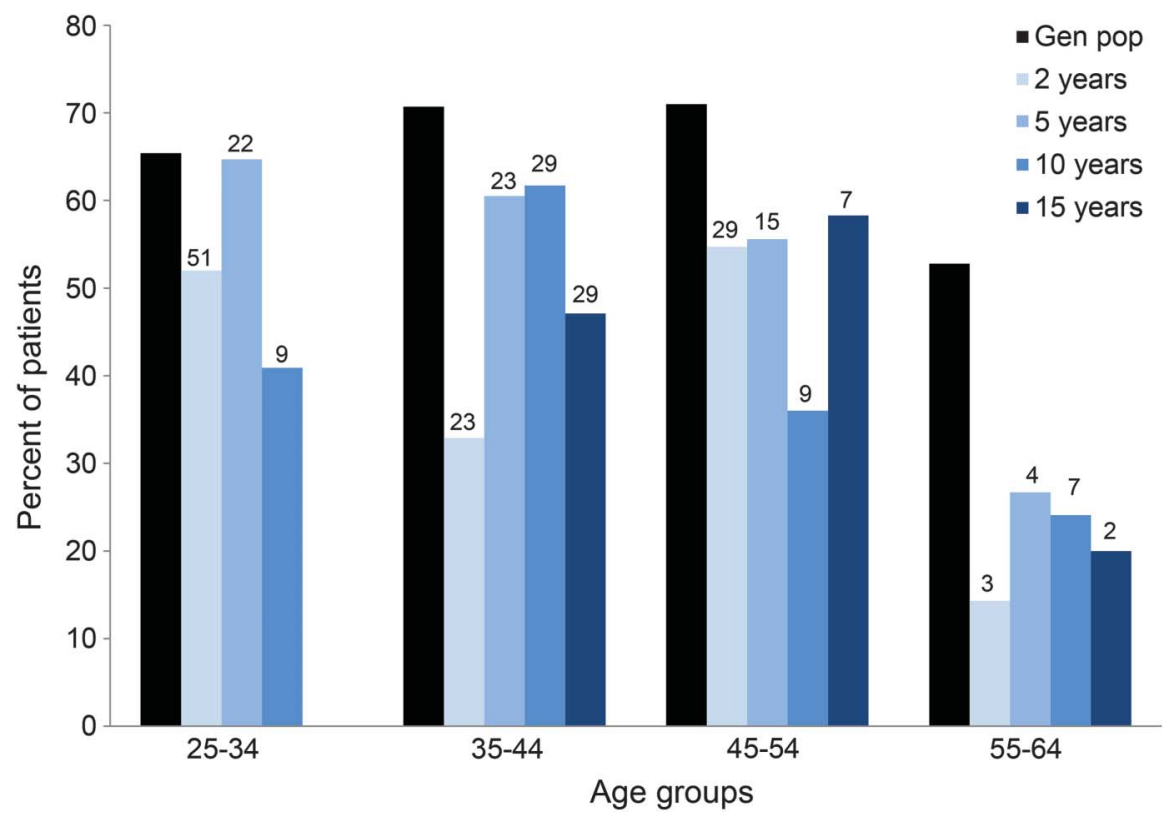

Percentage with full-time employment in the general population and in seizure-free patients in different age groups. Numbers above bars represent number of patients in each group. Gen pop = general population.

DISCUSSION In this longitudinal observational study of employment outcomes after resective epilepsy surgery in adults, there were no major changes in employment outcome at group level: the percentage of patients in employment (full- or part-time) at baseline, and after 2, 5, 10, and 15 years, respectively, was 52\%, 52\%, 57\%, 53\%, and $44 \%$. At subgroup level, patients with full-time employment at baseline who became seizure-free after surgery had the best chances to continue working. However, over time, a declining proportion of patients worked full time, indicating that seizure freedom alone is not enough to retain full-time working capacity. Students had similar employment outcomes as those with preoperative full-time employment, which has been found in earlier studies after temporal lobe resection., ${ }^{3,10}$ Possible reasons could be younger age and shorter duration of epilepsy, factors that have been shown previously to be associated with better employment outcome. ${ }^{7,9,10,25}$ Sixteen percent of seizure-free patients who were receiving benefits at baseline worked full time at 2 years, increasing to approximately $30 \%$ after 5 and 10 years, demonstrating that these changes often take more than 2 years to achieve. Although this is less than for patients employed preoperatively, it is an encouraging finding. In comparison, a prospective multicenter US study found that full-time employment increased modestly from 39.5\% presurgery to $42.8 \% 2$ years postsurgery. Twentyfive percent of those disabled or unemployed before surgery had gained employment after 2 years and this was associated with better seizure outcome. $^{5}$

Results from longer-term vocational outcome studies after epilepsy surgery are not consistent. One study from Philadelphia (mean follow-up 10 years) found that full-time employment had increased from $44 \%$ preoperatively to $52 \%$ postoperatively and unemployment decreased from $36 \%$ to $22 \% .{ }^{10}$ By contrast, in a study from Detroit, $42 \%$ worked full time preoperatively, but after a mean of 10.6 years, only $23 \%$ were still in full-time employment (28\% of those with favorable seizure outcome vs $8 \%$ of those with unfavorable outcome). ${ }^{26}$ One interpretation of these findings is that cross-sectional studies are sensitive to the current state of the labor market and that people with health problems may have more difficulties in finding or retaining work in times of recession. Methodologic drawbacks with retrospective studies and different selection and exclusion criteria might also explain some of the differences obtained. The longitudinal design of the present study and the comparison to the general population compensate for some of these factors. One interesting finding in our study was that not all patients who worked full time at baseline and became seizure-free worked full time postoperatively. Reasons for this could include complications or expected adverse events after surgery. Also, a proportion of seizure-free patients retired or went from full-time to part-time work earlier than the general population. The reasons for this need to be further investigated. One possibility is that having had epilepsy for half of a person's life leads to 


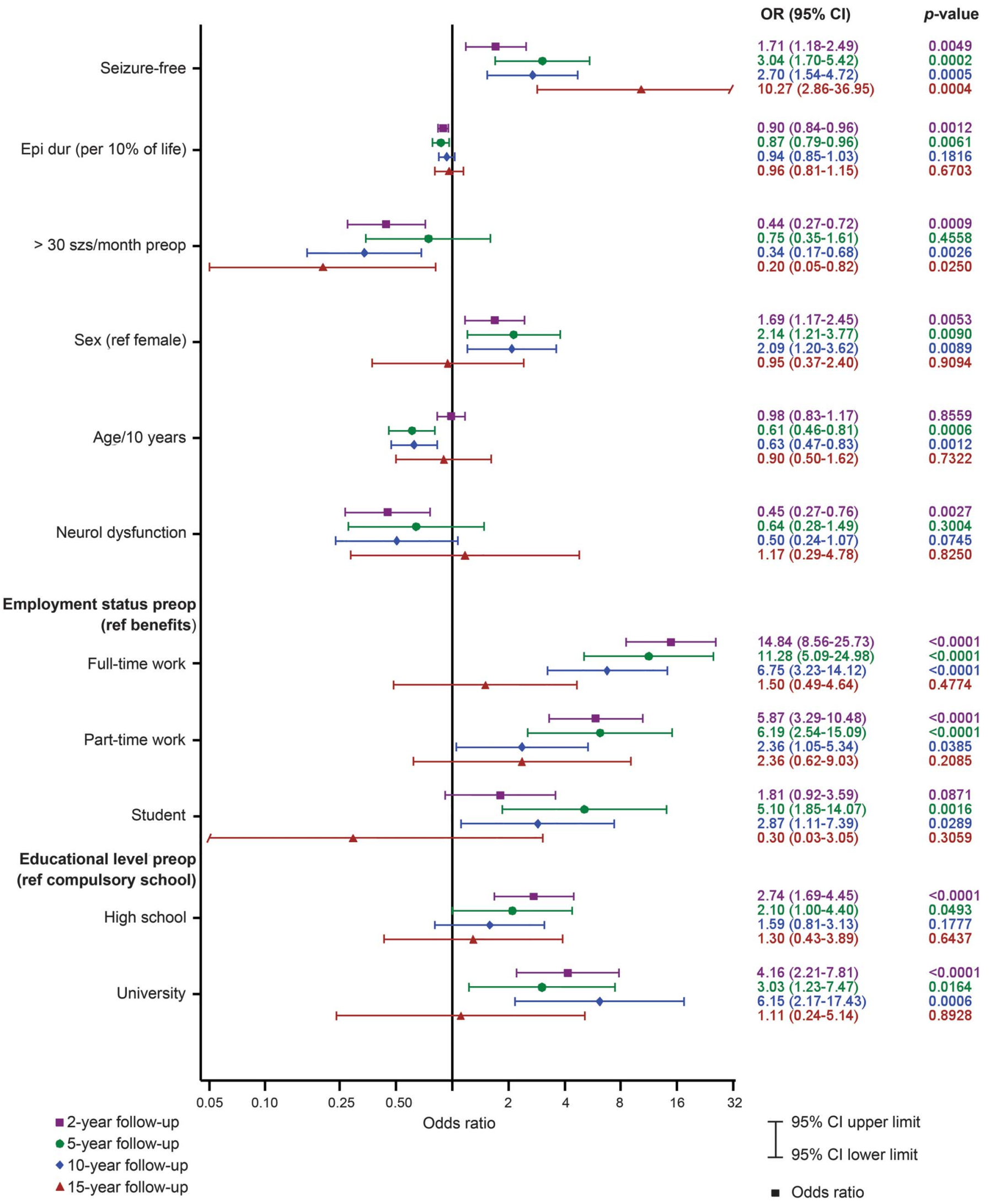

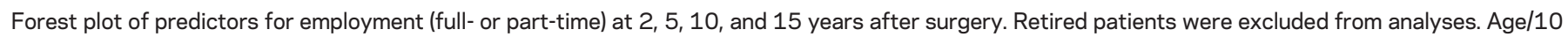

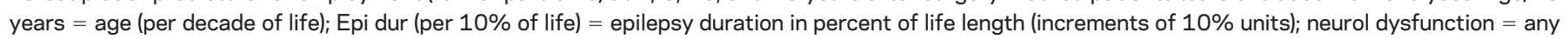

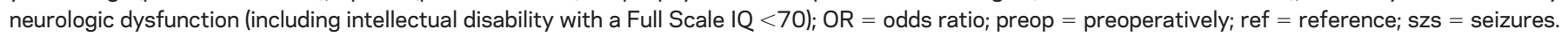




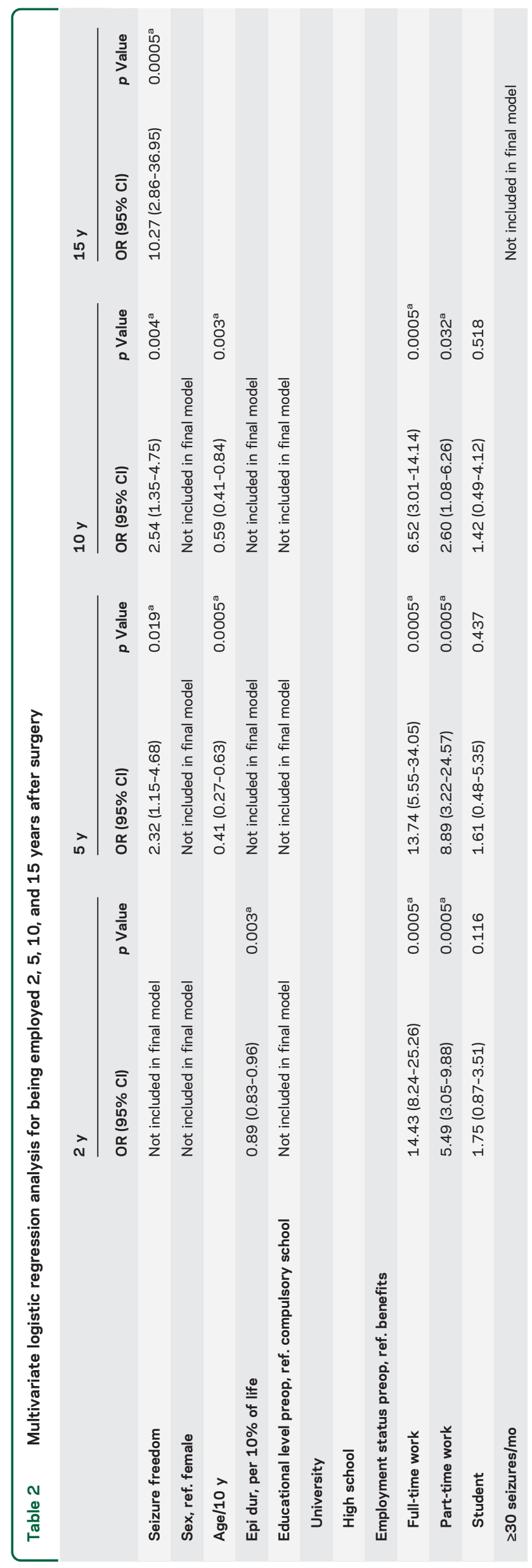

impairments that may not always be measurable and these may become more apparent with age. This together with the fact that a proportion of patients after surgery have some further cognitive impairment could be factors of importance. There are studies showing that people with supposedly stable neurologic dysfunctions also have reduced long-term working capacity. In a Swedish follow-up study of young adults with cerebral palsy or spina bifida, full-time employment declined and the number receiving benefits increased over 12 to 14 years. ${ }^{27}$ One might speculate that the aging process influences people with disabilities earlier.

AED polytherapy has been suggested to be associated with lower employment rates..$^{28}$ One of several reasons for this could be side effects. In our study, seizure-free employed patients had fewer AEDs than seizure-free unemployed patients at 2 and 5 years. It is possible that a decreased drug load is beneficial for the ability to work.

Ability to drive has been explored in some studies and was not associated with employment in one study, ${ }^{\text {? }}$ but associated with employment in others. ${ }^{3,6,29}$ In our study, there was an association between full-time work and ability to drive at 5 and 10 years. The same pattern was found concerning family and living conditions, whereby patients with full-time employment more often had families of their own. All these factors indicate that patients in full-time employment have a higher general psychosocial functioning level, being less vulnerable to the impact of having epilepsy. Whether this is of equal or even greater importance for good vocational outcome after epilepsy surgery than seizure freedom is unclear. Other factors of probable importance for retaining or obtaining work, such as postoperative cognitive level and psychiatric or other comorbidities, could not be addressed in this register study.

In our study, the multivariate predictors for longterm employment were preoperative employment, seizure freedom, and younger age at surgery. Employment at baseline was the strongest predictor of employment after surgery, but the odds ratio (OR) declined over the years. One other study found that patients who were students or had full-time employment had an OR of 16 to be in full-time employment after a mean of 4 years. ${ }^{3}$ In our study, seizure freedom was an independent predictor of employment and had an OR of 2.5-3 between 2 and 10 years for being employed. Other studies have also found an association between seizure outcome and employment. ${ }^{3,25,30}$ In univariate analyses, the preoperative level of education had high ORs for being employed but lost its significance in the multivariate logistic regression, which is interpreted to be attributable to the fact that the level of education is closely associated with being employed. Younger age at surgery was an independent predictor 
of better vocational outcome, emphasizing the importance of early referral of patients with drug-resistant epilepsy for presurgical evaluation.

The importance of rehabilitation after epilepsy surgery was highlighted in a recent study showing that participation in a rehabilitation program had the same impact as seizure freedom on employment outcome. ${ }^{31}$ Further investigations of the effects of rehabilitation programs on vocational outcomes are warranted.

The strengths of this study are that SNESUR provides population-based, prospective, and longitudinal data and that employment levels in our patient cohorts could be compared with the general Swedish population. Our cohorts are large with few patients missing at follow-ups. Longitudinal follow-up at regular intervals makes it possible to follow changes over time and decrease the sensitivity to variations in macroeconomic conditions (e.g., recessions), which are likely to affect employment outcomes. One weakness of our study is that yearly follow-up data were not available, precluding analysis of patterns of relapse and remission as well as individual trajectories of seizure and vocational outcomes. Also, the extent of part-time work is not reported and there is no information that can provide occupational classification. The study also lacks a control group of medically treated patients.

While there were no net employment gains at group level, patients who worked preoperatively and became seizure-free were shown to have the best vocational outcomes. Seizure freedom alone did not imply full-time working capacity in the long term and the prospects of returning to work were not as good as of retaining work. Earlier presurgical evaluation cannot be assumed per se to lead to a better vocational outcome after successful surgery. However, it is the single most important factor possible to influence, and since younger age was an independent predictor of good employment outcome, it is not unreasonable to believe that earlier referrals could improve vocational outcomes.

\section{AUTHOR CONTRIBUTIONS}

Dr. Edelvik has analyzed and interpreted the data and written the manuscript. Dr. Flink is manager of the Swedish Epilepsy Surgery Register and has assisted with data analysis. Dr. Malmgren has designed the study, interpreted data, and revised the manuscript.

\section{ACKNOWLEDGMENT}

The authors thank Mattias Molin at Statistiska Konsultgruppen in Gothenburg for assistance with statistical analysis, all of the Swedish epilepsy surgery teams (Gothenburg, Linköping, Lund, Stockholm, Umeå, and Uppsala), the steering committee of the SNESUR, and Sahlgrenska University Hospital, Gothenburg, Sweden.

\section{STUDY FUNDING}

The study was funded by grants from the Swedish Research Council (grant 521-2011-169), Sahlgrenska Academy, University of Gothenburg through the LUA/ALF agreement (grant ALFGBG137431), the Gothenburg Foundation for Neurological Research, and the Gothenburg Medical Society.

\section{DISCLOSURE}

A. Edelvik received speaker honoraria from UCB and Eisai. R. Flink reports no disclosures relevant to the manuscript. K. Malmgren served on an educational advisory board for UCB and received speaker honoraria from UCB and Biogen Idec. Go to Neurology.org for full disclosures.

Received March 19, 2015. Accepted in final form June 29, 2015.

\section{REFERENCES}

1. Augustine EA, Novelly RA, Mattson RH, et al. Occupational adjustment following neurosurgical treatment of epilepsy. Ann Neurol 1984;15:68-72.

2. Wass CT, Rajala MM, Hughes JM, et al. Long-term follow-up of patients treated surgically for medically intractable epilepsy: results in 291 patients treated at Mayo Clinic Rochester between July 1972 and March 1985. Mayo Clin Proc 1996;71:1105-1113.

3. Reeves AL, So EL, Evans RW, et al. Factors associated with work outcome after anterior temporal lobectomy for intractable epilepsy. Epilepsia 1997;38:689-695.

4. Maehara T, Inaji M, Matsuura M. Surgical effects of focus resection for patients with intractable epilepsy. Neurol Med Chir 2013;53:281-286.

5. Chin PS, Berg AT, Spencer SS, et al. Employment outcomes following resective epilepsy surgery. Epilepsia 2007; 48:2253-2257.

6. Asztely F, Ekstedt G, Rydenhag B, Malmgren K. Long term follow-up of the first 70 operated adults in the Goteborg Epilepsy Surgery Series with respect to seizures, psychosocial outcome and use of antiepileptic drugs. J Neurol Neurosurg Psychiatry 2007;78:605-609.

7. Sperling MR, Saykin AJ, Roberts FD, French JA, O'Connor MJ. Occupational outcome after temporal lobectomy for refractory epilepsy. Neurology 1995;45:970-977.

8. Jones JE, Berven NL, Ramirez L, Woodard A, Hermann BP. Long-term psychosocial outcomes of anterior temporal lobectomy. Epilepsia 2002;43:896-903.

9. George L, Iyer RS, James R, Sankara Sarma P, Radhakrishnan K. Employment outcome and satisfaction after anterior temporal lobectomy for refractory epilepsy: a developing country's perspective. Epilepsy Behav 2009;16: 495-500.

10. Zarroli K, Tracy JI, Nei M, Sharan A, Sperling MR. Employment after anterior temporal lobectomy. Epilepsia 2011;52:925-931.

11. Perry MS, Duchowny M. Surgical versus medical treatment for refractory epilepsy: outcomes beyond seizure control. Epilepsia 2013;54:2060-2070.

12. Chin PS, Berg AT, Spencer SS, et al. Patient-perceived impact of resective epilepsy surgery. Neurology 2006;66: 1882-1887.

13. Taylor DC, McMacKin D, Staunton H, Delanty N, Phillips J. Patients' aims for epilepsy surgery: desires beyond seizure freedom. Epilepsia 2001;42:629-633.

14. Hedegard E, Bjellvi J, Edelvik A, Rydenhag B, Flink R, Malmgren K. Complications to invasive epilepsy surgery workup with subdural and depth electrodes: a prospective population-based observational study. J Neurol Neurosurg Psychiatry 2014;85:716-720.

15. Malmgren K, Olsson I, Engman E, Flink R, Rydenhag B. Seizure outcome after resective epilepsy surgery in patients with low IQ. Brain 2008;131:535-542.

16. Nilsson L, Ahlbom A, Farahmand BY, Tomson T. Mortality in a population-based cohort of epilepsy surgery patients. Epilepsia 2003;44:575-581. 
17. Rydenhag B, Flink R, Malmgren K. Surgical outcomes in patients with epileptogenic tumours and cavernomas in Sweden: good seizure control but late referrals. J Neurol Neurosurg Psychiatry 2013;84:49-53.

18. Edelvik A, Rydenhag B, Olsson I, et al. Long-term outcomes of epilepsy surgery in Sweden: a national prospective and longitudinal study. Neurology 2013;81:1244-1251.

19. Rydenhag B, Silander HC. Complications of epilepsy surgery after 654 procedures in Sweden, September 1990 1995: a multicenter study based on the Swedish National Epilepsy Surgery Register. Neurosurgery 2001;49:51-56; discussion 56-57.

20. Wieser HG, Blume WT, Fish D, et al. ILAE Commission Report. Proposal for a new classification of outcome with respect to epileptic seizures following epilepsy surgery. Epilepsia 2001;42:282-286.

21. Guldvog B, Loyning Y, Hauglie-Hanssen E, Flood S, Bjornaes H. Surgical versus medical treatment for epilepsy: II: outcome related to social areas. Epilepsia 1991;32: 477-486.

22. Reid K, Herbert A, Baker GA. Epilepsy surgery: patientperceived long-term costs and benefits. Epilepsy Behav 2004;5:81-87.

23. Andersson-Roswall L, Engman E, Samuelsson H, Malmgren K. Psychosocial status 10 years after temporal lobe resection for epilepsy, a longitudinal controlled study. Epilepsy Behav 2013;28:127-131.

24. Edelvik A, Flink R, Rydenhag B, Malmgren K. Prospective longitudinal 10-year employment and seizure outcome of resective epilepsy surgery in Sweden. Abstracts from 9th
European Congress on Epileptology in Rhodes 2010. Epilepsia 2010;51:44.

25. Lendt M, Helmstaedter C, Elger CE. Pre- and postoperative socioeconomic development of 151 patients with focal epilepsies. Epilepsia 1997;38:1330-1337.

26. Wasade VS, Elisevich K, Tahir R, et al. Long-term seizure and psychosocial outcomes after resective surgery for intractable epilepsy. Epilepsy Behav 2015;43C:122-127.

27. Tornbom M, Jonsson U, Sunnerhagen KS. Work participation among middle-aged persons with cerebral palsy or spina bifida: a longitudinal study. Disabil Health J 2014;7: 251-255.

28. Haag A, Strzelczyk A, Bauer S, Kuhne S, Hamer HM, Rosenow F. Quality of life and employment status are correlated with antiepileptic monotherapy versus polytherapy and not with use of "newer" versus "classic" drugs: results of the "Compliant 2006" survey in 907 patients. Epilepsy Behav 2010;19:618-622.

29. Dupont S, Tanguy ML, Clemenceau S, Adam C, Hazemann P, Baulac M. Long-term prognosis and psychosocial outcomes after surgery for MTLE. Epilepsia 2006; 47:2115-2124.

30. Lazow SP, Thadani VM, Gilbert KL, et al. Outcome of frontal lobe epilepsy surgery. Epilepsia 2012;53: $1746-1755$.

31. Thorbecke R, May TW, Koch-Stoecker S, Ebner A, Bien CG, Specht U. Effects of an inpatient rehabilitation program after temporal lobe epilepsy surgery and other factors on employment 2 years after epilepsy surgery. Epilepsia 2014;55:725-733.

\section{Introducing EBM Online-FREE to AAN Members!}

The American Academy of Neurology again demonstrates its commitment to high-quality neurology education by converting and refining its popular classroom evidence-based medicine training into a convenient on-demand, self-paced online program. Only EBM Online from the AAN provides the trusted expertise of the source of the world's most respected neurology guidelines.

EBM Online:

- Features five hours of convenient, interactive courses in 10 modules

- Uses common, real-life neurologic clinical examples

- Measures outcomes with pre-test, post-test, and module evaluations

- Provides helpful feedback on individual knowledge and more

This program is available now to residents and fellows; practicing neurologists are encouraged to register when CME is available in 2016.

Learn more at AAN.com/view/EBMOnline. 


\section{Neurology}

Prospective and longitudinal long-term employment outcomes after resective epilepsy surgery

Anna Edelvik, Roland Flink and Kristina Malmgren

Neurology 2015;85;1482-1490 Published Online before print September 25, 2015

DOI 10.1212/WNL.0000000000002069

This information is current as of September 25, 2015

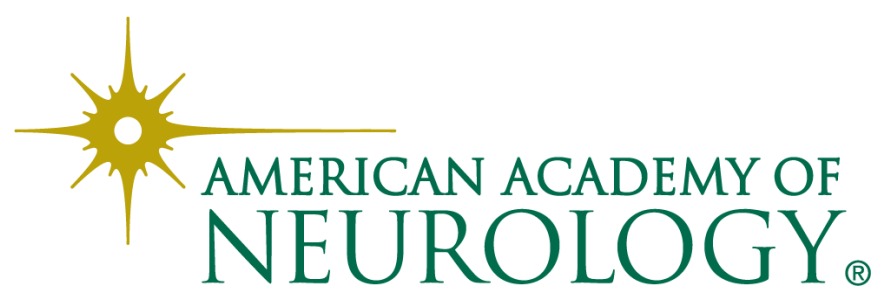




\section{Updated Information \& Services}

\section{Supplementary Material}

\section{References}

Citations

Subspecialty Collections

Permissions \& Licensing

\section{Reprints}

including high resolution figures, can be found at: http://n.neurology.org/content/85/17/1482.full

Supplementary material can be found at: http://n.neurology.org/content/suppl/2015/09/26/WNL.0000000000002 069.DC1 http://n.neurology.org/content/suppl/2015/12/15/WNL.0000000000002 069.DC2

This article cites 31 articles, 6 of which you can access for free at: http://n.neurology.org/content/85/17/1482.full\#ref-list-1

This article has been cited by 1 HighWire-hosted articles: http://n.neurology.org/content/85/17/1482.full\#\#otherarticles

This article, along with others on similar topics, appears in the following collection(s):

All Epilepsy/Seizures

http://n.neurology.org/cgi/collection/all_epilepsy_seizures

Cohort studies

http://n.neurology.org/cgi/collection/cohort_studies

Epilepsy surgery

http://n.neurology.org/cgi/collection/epilepsy_surgery_

Outcome research

http://n.neurology.org/cgi/collection/outcome_research

Information about reproducing this article in parts (figures,tables) or in its entirety can be found online at:

http://www.neurology.org/about/about_the_journal\#permissions

Information about ordering reprints can be found online:

http://n.neurology.org/subscribers/advertise

Neurology ${ }^{\circledR}$ is the official journal of the American Academy of Neurology. Published continuously since 1951, it is now a weekly with 48 issues per year. Copyright (C) 2015 American Academy of Neurology. All rights reserved. Print ISSN: 0028-3878. Online ISSN: 1526-632X.

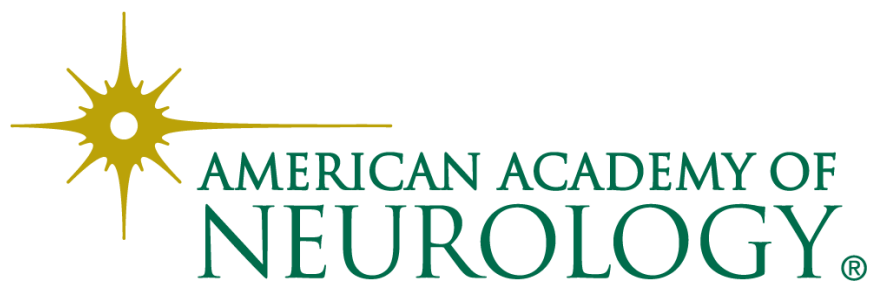

